\title{
Contribuições das produções sobre a complexidade: aportes para a educação científica escolar
}

Giselle Watanabe ${ }^{1}$

Universidade Federal do ABC

Santo André - SP

Maria Regina Dubeux Kawamura ${ }^{1}$

Universidade de São Paulo

São Paulo - SP

\section{Resumo}

A perspectiva da complexidade anuncia uma forma de pensar e agir frente às situações da realidade que, de modo geral, referem-se a sistemas abertos e dinâmicos. Para buscar aproximações com essa perspectiva e propor sua efetiva incorporação nas ações dos sujeitos, nos parece fundamental considerá-la no processo educacional, por meio de diferentes dimensões: Dimensão Educacional, Dimensão de EnsinoAprendizagem e Dimensão Epistemológica. Cada uma dessas Dimensões incorpora a complexidade em contextos distintos da educação $e$ formação científica escolar. Elas, ainda em construção, buscam organizar alguns elementos da complexidade que podem mobilizar os sujeitos para uma mudança de paradigma. Nossa hipótese é a de que essas Dimensões, ao permear os discursos e as ações docentes, contribuam para uma formação mais complexa, próxima da realidade dos sujeitos. Diante disso, esse artigo busca investigar de que forma as questões da complexidade estão presentes nas produções de membros de grupos de pesquisa espanhóis que as incorporam no contexto da educação científica escolar. Ao investigar tais grupos, pretende-se aprofundar o sentido dessas Dimensões e suas especificidades, através de aproximações não nacionais. Metodologicamente, a pesquisa compreende dois momentos: (1) identificação dos pontos de partida de aspectos da complexidade na Dimensão Educacional, na Dimensão

\footnotetext{
${ }^{+}$Contributions of complexity productions: subsidies to scholar scientific education

* Recebido: maio de 2019. Aceito: junho de 2020.

${ }^{1}$ E-mails: giselle.watanabe@ufabc.edu.br; kawamura@if.usp.br
} 
Ensino-Aprendizagem e na Dimensão Epistemológica; e (2) identificação desses aspectos, tomando como material de referência as produções em periódicos de alguns grupos educacionais espanhóis especialistas no assunto. Para análise dos dados, considerar-se-á a Análise Textual Discursiva, tomando como parâmetro a perspectiva da complexidade e as estratégias usuais em estudos etnográficos. Dentre os resultados, constata-se uma significativa convergência de perspectivas, ainda que com matizes. Reitera-se que uma mudança nas propostas de educação cientifica, que busquem ir além de um pensamento simples e trabalhar na perspectiva mais complexa, é potencializada quando a complexidade leva em conta, de forma articulada, aspectos de todas suas Dimensões. Ou seja, uma educação para a complexidade requer que ela seja incorporada em um conjunto de ações/atitudes/ reflexões; caso contrário, a escola está apenas acentuando alguns modos de pensar e atuar que podem levar apenas às mudanças pontuais e individualizadas.

Palavras-chave: Educação Científica Escolar; Ensino de Física; Dimensões; Complexidade.

\begin{abstract}
Complexity perspective announces a way of thinking and acting in consideration of situations from the reality that, in general, refer to open and dynamic systems. To investigate the approaches in this perspective and to propose its effective incorporation in subject actions, it is fundamental to consider it in the educational process through different dimensions: Educational Dimension, Teaching-Learning, and Epistemological Dimension. Any Dimension incorporates complexity in different contexts of school education and scientific scholar training. In their construction, they seek to organize elements of complexity that can mobilize the subjects for a paradigm shift. We hypothesize that these dimensions contribute to a more complex formation by permeating teaching discourses and actions closer to the subjects' reality. Based on that, this article investigates how complex issues are present in the productions of members of Spanish research groups which incorporate them in the context of Science school education. It is intended to deepen the meaning of these Dimensions and their specificities, when investigating such groups, by non-national approaches. Methodologically, this research is comprised by two moments: (1) identification of starting points of the aspects of complexity in the
\end{abstract}


Educational Dimension in the Teaching-Learning Dimension and the Epistemological Dimension; and (2) identification of these aspects, selecting the productions in journals of some Spanish groups specialized in the subject matter as a material of reference. For data analysis, Discursive Textual Analysis will be considered, assuming the perspective of complexity and the usual strategies in ethnographic studies as parameters. Among the results, there is a significant convergence of perspectives, albeit with nuances. It is emphasized that a change of proposals for scientific education, which seeks to go further than simply understanding and working in a more complex perspective, which is enhanced when complexity is articulated, involving aspects of all dimensions. Therefore, the education for complexity requires that it should be incorporated into a set of actions/attitudes/ reflections; otherwise, the school is only accentuating ways of thinking and acting which may lead to specific and individualized changes.

\section{Keywords: School Scientific Education; Physical Education;} Dimension; Complexity.

\section{Introdução}

Novas demandas educacionais apontam para uma formação mais ampla, que considere um sujeito conectado e articulado com os problemas do mundo em que vive. Essa proposição vem pautada por diversos discursos que sinalizam a necessidade de que, para além dos conhecimentos disciplinares, a escola deva tratar também de questões de natureza social, econômica, ambiental, política, dentre outras. Implica, ainda, no que diz respeito a questões socioambientais, em reconhecer que as sociedades estão pautadas pela lógica do crescimento econômico e do hiperconsumo, desconsiderando as limitações e taxas de renovação dos recursos naturais. Esses elementos levam a uma lógica de crescimento pelo próprio crescimento.

Discursos com esta tônica, decorrentes de alguns países europeus e mais atualmente dos governos brasileiro e estadunidense, vem sendo usados nos debates que nutrem a ideia acerca da necessidade de descomplexificar. A abordagem assumida, especialmente pela bancada política da extrema direita, leva a uma perspectiva reducionista e extremista, apontando para a manutenção de um sistema educativo que falha ao formar sujeitos capazes de construir uma sociedade mais digna e justa. Em especial, alegam que a descomplexificação é necessária para tratar o crescimento ou, em outras palavras, sugerem descomplexificar para avançar (FERNÁNDEZ; GONZÁLEZ, 2014; CASAL, 2016; PRATS; HERRERO; TORREGO, 2016; TAIBO; 2016). Em trabalho recente, García e Watanabe (2019), ao contrário, mostraram que a complexificação é fundamental para se pensar uma sociedade em 
decrescimento, no sentido de Latouche (2009). O autor propõe o decrescimento, que não se trata de crescer menos, como um projeto político. Salienta que são necessárias mudanças "capazes de desencadear um processo de decrescimento sereno, convivial e sustentável", voltadas a (i) reavaliar, (ii) reconceituar, (iii) reestruturar, (iv) redistribuir, (v) relocalizar, (vi) reduzir, (vii) reutilizar e (viii) reciclar (LATOUCHE, 2009). A lógica de decrescimento está intimamente ligada ao ser humano, à preservação, à justiça, à isonomia entre os humanos e entre eles e o ambiente. Em essência, está ligada ao respeito e à sensatez de não subjugar a natureza nem outras culturas.

Para nós, uma primeira aproximação a esse problema, a fim de esclarecê-lo, implicaria em considerar aspectos da complexidade para buscar uma formação que esteja também preocupada com questões abertas e dinâmicas, pautadas na realidade dos sujeitos, tal como as questões socioambientais são capazes de fazer. Nesse sentido, por exemplo, tratar da questão da energia implicaria em considerar as distintas formas que ela assume, suas possibilidades de transformação, recursos e limites, os interesses econômicos e políticos que a envolvem. Mas, também, as questões científicas mais profundas, que incluiriam os aspectos entrópicos, para explicar perspectivas de seu futuro, relacionadas aos impactos e riscos que implicam sua inserção nos sistemas sociais atuais.

Para pautar-se em aspectos da complexidade, entretanto, é importante sinalizar que há diferentes faces e abordagens para seu entendimento, em diferentes campos do saber, tal como sinalizado em Watanabe (2012). A complexidade, segundo estudos realizados por Fiedler-Ferrara (1998), pode ser entendida enquanto uma forma de tratar um grande número de elementos; uma dificuldade de descrição de sistemas cujo conjunto de informações não permite seu pleno entendimento; a medida de 'complicação' frente à quantidade de etapas necessárias para descrever um sistema; a medida de dificuldades em juntar partes de um sistema não se tornando propriedade do objeto, mas processo para compor o objeto; dentre outras. Ainda, segundo Cini (1994), é possível identificar na ciência diferentes abordagens, que se configuram como diferentes linguagens. Nesse sentido, para além da linguagem das determinações (característica da física clássica) e da linguagem das indeterminações (característica da física moderna), há de se considerar a linguagem da complexidade. Essa última, na segunda metade do século $\mathrm{XX}$, tem origem nas sistematizações para se descrever comportamentos caóticos.

A complexidade nas Ciências Naturais aparece em temas como a evolução e seleção natural; funcionamentos do sistema nervoso central; dinâmicas dos fenômenos naturais; sistemas não lineares, questão de ordem e caos; modelo autocatalítico da origem da vida; entre outros (NUSSENZVEIG, 2003). Na perspectiva da Química, as teorias do caos e de auto-organização são base para o estudo das reações químicas oscilantes. Na Ecologia, a complexidade comparece na construção de modelos não lineares presentes, por exemplo, na dinâmica de populações, com destaque para a variabilidade microscópica e aleatoriedade (nascimento e morte) e mutações. Na Epidemiologia e Imunologia, os trabalhos estão 
pautados em modelos de reprodução de comportamentos e resultados complexos do mundo real. No âmbito das Ciências Humanas e da Saúde, especificamente na Psicologia, a complexidade aparece nos tratamentos que vinculam os problemas psíquicos ao sistema físico, emocional e social. Na Geografia, os estudos comparecem na interpretação do sistema mundial, visto como um sistema composto por diversos níveis de organização (municipal, estadual etc.) e sistemas de ação (geopolítico, econômico, ideológico, ecológico etc.). $\mathrm{Na}$ Sociologia, a complexidade é tratada nas mutações e inovações que surgem na esfera social, buscando, por exemplo, explicar o fato de a sociedade apresentar uma dinâmica relativamente ordenada e regular, mesmo tendo influências individuais pouco organizadas. A perspectiva da complexidade também aparece nos estudos de Economia ao tratar, por exemplo, questões relacionadas à dinâmica não linear que surge na interação entre as forças que compõe a sociedade (estado, grupos sociais etc.). Nesse contexto, as relações estabelecidas podem conduzir às situações de auto-organização do sistema ou a destruição das estruturas regulares, ocasionando a desestabilização ou a bifurcação. A teoria da complexidade aparece, também, na análise sobre os componentes instáveis da bolsa de valores (FIELDLER-FERRARA, 2003).

No âmbito educacional, há uma preocupação em lidar com assuntos complexos, procurando estabelecer ações e reflexões que levem a uma formação mais abrangente e crítica dos sujeitos. Isso implica em contrapor-se à estrutura conceitual rígida, em que imperam a organização linear de conceitos e conteúdos, e à forma determinista de articulá-los, embora sempre incluindo e contemplando os conhecimentos científicos pertinentes. A complexidade aqui defendida, não se trata de reduzi-la ou confundi-la com a interdisciplinaridade. Ou seja, ainda que a complexidade abarque aspectos interdisciplinares, principalmente por sua conexão estreita com as questões sociais, há de se considerar as suas relações fundamentais com a realidade, com os problemas abertos e dinâmicos e com as situações de riscos e incertezas. Nessa linha, destacam-se as propostas pautadas por uma abordagem da complexificação do conhecimento cotidiano escolar (GARCÍA, 1998; 2004a; 2004b); por uma educação sustentável a partir de preceitos do paradigma da complexidade (BONIL; JUNYENT; PUJOL, 2010); e por ações simultâneas pautadas pela complexidade representadas pelas Dimensões Educacional, Ensino-Aprendizagem e Epistemológica (WATANABE, 2012). Especificamente essas Dimensões referem-se aos elementos organizadores das reflexões do presente artigo.

Essa breve análise indica que há diferentes reflexões que podem contribuir para uma formação mais consistente do ponto de vista da complexidade e de seu papel na educação. Em pesquisa atual (WATANABE; RODRIGUEZ-MARÍN, 2018), é possível perceber que sujeitos de formações em distintas áreas do conhecimento mantêm um discurso da complexidade contemplando apenas os graus de complicação de um sistema, contra o que já alertava Morin $(2007$; 2009). Essa visão limitada, do nosso ponto de vista, inviabiliza uma mudança na forma de lidar com grande parte das questões enfrentadas pela sociedade dando 
espaço, inclusive, para que discursos pautados na descomplexificação ganhem destaque. No mesmo estudo e em uma pesquisa de pós-doutorado de uma das autoras, também foi possível identificar dois grupos espanhóis que abordam o assunto sob outro enfoque, mais próximos da perspectiva da complexidade e da criticidade. São eles: Investigación y Renovación Escolar (IRES), da Universidad de Sevilla (US), e Complèx, da Universitat Autònoma de Barcelona (UAB). Em seus discursos, são notórias as intencionalidades pela busca por uma educação pública na qual sejam formados cidadãos mais críticos e pautados em um pensamento complexo, capazes de exercerem suas atividades de forma digna e democrática.

Em suma, para que possamos nos posicionar frente às questões nas quais as incertezas e riscos estão presentes, parece essencial viabilizar um posicionamento coerente com um mundo em transformação. Para nós, essa mudança requer incorporar, nos processos de formação, a perspectiva da complexidade. Requer considerar, por exemplo, uma formação escolar organizada a partir de temas abertos e dinâmicos, como na abordagem de questões socioambientais. E por que as questões socioambientais? De certo, porque elas trazem espaços para posicionamentos pautados em discursos científicos legítimos, podendo explicitar diferentes pontos de vista, tanto críticos como até mesmo céticos ou ortodoxos. Ainda, porque permitem promover reflexões que explicitam as relações entre as distintas esferas do conhecimento; tratam de um assunto contemporâneo envolvendo situações de risco; elucidam as condições dinâmicas do planeta, podem mobilizar posicionamentos, além de outras potencialidades.

Diante dessas colocações, é evidente a abrangência do desafio de introduzir aspectos relativos à complexidade na educação e à necessidade de um maior aprofundamento na identificação dos mesmos. Tal aprofundamento requer, ainda que como uma primeira aproximação, investigar de que forma as questões da complexidade estão presentes nas produções de membros de grupos de pesquisa que as incorporam no contexto da educação científica escolar. Ou seja, para aqueles grupos de pesquisa que trabalham com aspectos complexidade no contexto escolar, quais aportes podem contribuir para uma formação mais complexa?

Tomando essa investigação como ponto de partida, acreditamos ser possível construir uma maior sistematização e articulação dos enfoques da complexidade a serem contemplados. E, nesse sentido, consideramos essencial partir e sinalizar aspectos já presentes e desenvolvidos em reflexões ou práticas anteriores, tomando, para isso, os trabalhos dos grupos que podem fornecer importantes indícios do que priorizar. Como matriz para nossa análise, partimos da hipótese de que considerar as Dimensões Educacional, EnsinoAprendizagem e Epistemológica (WATANABE, 2012) pode permitir uma abordagem relevante para as finalidades desejadas. 


\section{Dimensões de análise: Educacional, Ensino-Aprendizagem e Epistemológica}

Consideramos que as Dimensões Educacional, Ensino-Aprendizagem e Epistemológica permitem estruturar um conjunto de ações e atitudes que estão sempre presentes nos processos educacionais. Embora isso possa dizer respeito à educação de forma abrangente, reveste-se de especificidades. Em relação à perspectiva da complexidade, elas são o resultado de um conjunto de pressupostos advindos de um estudo criterioso (WATANABE, $2012)^{2}$, que buscou organizar aspectos para formar sujeitos nessa perspectiva, desde sua forma de pensar até agir e refletir. Essas Dimensões referem-se aos três espaços necessários para incorporar aspectos da complexidade visando à formação mais ampla do sujeito. Nosso pressuposto é de que, se contemplarmos apenas uma ou duas delas, a formação para uma mudança de paradigma não ocorre em sua plenitude. Portanto, ensinar apenas o conceito de fractais ou o expoente de Layuponov em sistemas dinâmicos, por exemplo, não garantiriam uma formação para a complexidade. Salienta-se que os elementos que constituem essas Dimensões vão se construindo ao longo das nossas reflexões e ao longo do tempo, em um processo aberto e dinâmico. De antemão, essas Dimensões também vão estabelecer a metodologia da pesquisa.

$\mathrm{Na}$ Dimensão Educacional (DE) o foco está em tratar os pressupostos essenciais para educar na perspectiva mais complexa. Ou seja, os objetivos últimos e as finalidades da educação para a complexidade. Nesse sentido, considera-se uma formação na qual a(o) aluna(o) é protagonista na construção do seu conhecimento, considerando tal conhecimento indutor de comportamentos, valores e ações, o que, por sua vez, volta-se aos aspectos culturais e à visão de mundo que permeia uma sociedade. As questões que problematizam a DE são do tipo: Que cidadã(o) formar? Quais as suas principais características? O que considerar para que um problema aberto e da realidade seja efetivamente um problema da(o) estudante? De que forma esse problema pode se relacionar com as outras esferas do conhecimento? Ou seja, é um problema político, econômico, social e/ou ambiental?

Responder a essas questões, em especial ao tipo de sujeito que se quer formar, requer pensar em um problema aberto e complexo (e por isso a escolha pelo ambiente, como já salientado). Para nós, esse sujeito deve ser formado a partir de pressupostos indicados pela Educação Ambiental Crítica, Complexa e Reflexiva (EA $\mathrm{CCR}_{\text {) }}$ (WATANABE; KAWAMURA, 2014) que tem suporte nas reflexões de $\operatorname{Beck}^{3}$ (2010; 1997) e $\operatorname{Morin}^{4}$ (2009; 2007), além de

\footnotetext{
${ }^{2}$ Considera-se ainda as reflexões e estudos que vêm sendo resolvidos no âmbito do grupo de pesquisa brasileiro GrECC (Grupo em Ensino de Ciências e suas Complexidades), sediado na Universidade Federal do ABC.

${ }^{3}$ As reflexões de Beck $(2010 ; 1997)$ contribuem para se pensar nos espaços nos quais os indivíduos podem agir e se posicionar, considerando mudanças na esfera social caracterizada pelo conceito de sociedade de risco. Isso conduz a dois aspectos fundamentais: a formação de cidadãos na perspectiva da reflexividade, ou seja, autoconfrontadores, capazes de agir diante de situações de risco; e a necessidade de contemplar espaços de ação, caracterizados pelas subpolíticas.

${ }^{4}$ As reflexões de Morin $(2009 ; 2007)$ contribuem para repensar sobre as ações que podem ser efetivas nessa sociedade dinâmica e complexa, implicando numa outra forma de lidar com as mudanças, conduzida pelo pensamento complexo.
} 
alguns autores que tratam a Educação Ambiental Crítica. O termo Complexa considera que as ações socioambientais promovidas na escola e incorporadas no cotidiano dos indivíduos podem gerar mudanças de posturas que vão influenciar o modo de ver e se relacionar com o meio local e global. Dessa forma, procura-se (i) promover uma visão de ciência em que a simplificação e redução sejam incorporadas como elementos da complexificação; e (ii) considerar a complexidade da temática socioambiental no âmbito social, econômico, político e cultural, ou seja, ter clareza de que os problemas reais também têm interferências em outras esferas do conhecimento. Já os termos Crítico e Reflexivo referem-se a uma educação pautada na autoconfrontação que se estende antes, durante e após a tomada de decisão dos sujeitos. Isso significa buscar continuamente um posicionamento crítico e reflexivo de modo a prever os riscos, pautando-se, também, no princípio da precaução (LACEY, 2006). Ainda, estão presentes nessa Dimensão aspectos como contextualizar [preocupação com a dimensão espacial (local-global) e a dimensão temporal (passado, presente e futuro)], pensar criticamente (FREIRE, 2006), considerar o pensamento sistêmico, a ética, os valores e as emoções.

Na Dimensão Ensino-Aprendizagem (DEA) consideram-se os espaços de ação para a inserção da perspectiva da complexidade na escola, incorporando seu estatuto, função e currículo atual, assim como os obstáculos a serem superados. Inclui, também, as perspectivas para a ação de professoras(es), com ênfase em sua autonomia, explicitando possibilidades para a elaboração de suas propostas de aula. E a natureza da participação das(dos) estudantes, buscando seu protagonismo. Nesse âmbito, busca-se considerar ações que levem à mudança de um pensamento simples para um mais complexo. As questões que orientam as reflexões referentes à DEA são do tipo: Como estabelecer estudos de temas mais abertos e dinâmicos em sala de aula? Esses temas têm relação com a realidade das(os) estudantes? Essa realidade é local ou global? Como inserir essa discussão na escola? Quais conceitos e conteúdos contemplar? Considerar o currículo tradicional, trabalhando com enxertos, ou alterar a organização curricular? Quais os objetivos e as estratégias a serem adotados nas aulas, de forma a estimular a participação dos(as) estudantes?

Para nós, o desenvolvimento da complexidade no contexto da DEA implica no tratamento de um assunto na escola pelo viés temático, longe da linearidade dos currículos tradicionais. Busca-se um processo de desenvolvimento dos assuntos em sala de aula que seja dinâmico, dando a liberdade para os(as) docentes alterarem suas propostas conforme suas realidades; isso significa, por exemplo, pensar em estratégias que considerem percursos temáticos (WATANABE, 2012) e o conceito da redução temática (DELIZOICOV; ANGOTTI; PERNAMBUCO, 2002). Volta-se ainda a uma discussão pautada pela natureza do conhecimento escolar e nos pressupostos da complexificação do conhecimento cotidiano (GARCÍA, 1998; 2004a, 2004b), que leva à necessidade de identificar aspectos como as hipóteses de progressão e hipóteses de transição (GARCÍA, 1998; 2004a; 2004b; RODRIGUEZ-MARÍN; FERNÁNDEZ-ARROYO; GARCÍA, 2014). Na perspectiva de 
García (1998), o conhecimento escolar está vinculado aos aspectos mais amplos que envolvem, por exemplo, as relações com o meio. Isso significa que esse conhecimento não é uma transposição direta e única do conhecimento científico; mas, pelo contrário, é influenciado pelos conhecimentos científico, cotidiano e outras formas de conhecimento. $\mathrm{O}$ ponto de partida para a aprendizagem na escola é, portanto, o conhecimento cotidiano que deve ser enriquecido pelas diferentes formas de conhecimento (científico, culturais, técnicos etc.), tornando-se um conhecimento escolar. Quanto à forma como os sujeitos constroem esse conhecimento que, de antemão, é dotada de uma dimensão dinâmica e também não linear, García (1998) aponta para um conhecimento submetido a um processo de reorganização contínua, que leva a uma evolução, um processo aberto e irreversível, em que o novo é elaborado a partir do observável ou mediante alguns ajustes no sistema de ideias (assimilação, reestruturação fraca) ou por uma reorganização mais ampla (acomodação, reestruturação forte). Para o autor, é por meio da análise das ideias prévias das(os) estudantes que as hipóteses de transição, que se referem a sucessivos estados pelos quais passa um indivíduo durante a evolução do conhecimento, podem ser evidenciados. Tais hipóteses podem ser utilizadas tanto para orientar a(o) docente na elaboração dos conteúdos quanto para explicitar a evolução das ideias dos aprendizes.

Na Dimensão Epistemológica (DEp), destaca-se a inserção da perspectiva da complexidade no campo das Ciências Naturais, de sua abordagem e forma de tratar os objetos da ciência. Procura-se incorporar os conhecimentos da Física Clássica e Moderna, e, ao mesmo tempo, identificar e superar seus âmbitos, especialmente no que diz respeito ao reducionismo e à impossibilidade de previsões deterministas sobre a evolução de sistemas dinâmicos físicos. As questões que orientam as reflexões a DEp são do tipo: Qual a perspectiva da ciência mais adequada para tratar questões de natureza aberta e dinâmica, tais como as socioambientais? Em que espaços as distintas perspectivas de ciência (da determinação, da indeterminação e da complexidade) podem ser aplicadas? Nesta Dimensão pretende-se (i) identificar os conhecimentos científicos escolares relevantes; (ii) incorporar a linguagem da complexidade de forma a lidar com a imprevisibilidade, o acaso e a ordemdesordem etc.; (iii) considerar aspectos da Termodinâmica para promover reflexões sobre o sentido do tempo, os acontecimentos e o papel do acaso, além da irreversibilidade sob a perspectiva da entropia. Aqui também cabem discussões que tratam de aspectos que tenham como marco de referência as conexões, inter-relações, incerteza, teoria do caos, teoria dos sistemas, teoria da informação etc.

Para nós, a incorporação da perspectiva da complexidade na DEp inclui, ainda, discutir situações sobre Física do não equilíbrio, tais como defendidas por Prigogine (1988; 1993; 1996) e Isabelle Stengers (PRIGOGINE; STENGERS, 1984; 1992). Nelas ganham destaque conceitos como a irreversibilidade, 'flecha do tempo' e as peculiaridades da vida enquanto sistemas abertos, complexos, auto-organizado e longe do equilíbrio (GOULD, 1994; 1997; SCHNEIDER; KAY, 1997). Há também de se ter clareza acerca das diferentes 
linguagens da ciência, tomando como orientadoras as ideias de Cini (1994) e Prigogine (1996), ao levantarem elementos característicos das perspectivas das determinações, indeterminações e complexidade. Na DEp se apresenta a perspectiva da complexidade em complementaridade (mas não exclusão!) às abordagens da dinâmica newtoniana, buscando reconhecer essa linguagem no âmbito científico. Considera-se a ideia de um tempo construtivo diante dos processos irreversíveis e peculiaridades da vida. Sobre a vida, isso nos leva a uma abordagem que considere sistemas auto-organizados e longe do equilíbrio, introduzindo reflexões como as de Gould (1997) e Schneider e Kay (1997). Para esses últimos, ganha destaque a reinterpretação dos Princípios da Termodinâmica.

O Quadro 1 sistematiza alguns aspectos das Dimensões discutidos anteriormente, que são orientadores para analisar as produções que seguem.

Quadro 1 - Aspectos das Dimensões que orientam a análise das produções.

\begin{tabular}{|c|c|c|}
\hline & Principais questões orientadoras & Aspectos da complexidade \\
\hline DE & $\begin{array}{l}\text { Que cidadã(o) formar? Quais as suas } \\
\text { principais características? O que } \\
\text { considerar para que um problema aberto e } \\
\text { da realidade seja efetivamente um } \\
\text { problema da(o) estudante? De que forma } \\
\text { esse problema pode se relacionar com as } \\
\text { outras esferas do conhecimento? Ou seja, } \\
\text { é um problema político, econômico, } \\
\text { social e/ou ambiental? }\end{array}$ & $\begin{array}{l}\text { - Promoção de uma educação pautada por uma } \\
\text { postura complexa, crítica e reflexiva do sujeito } \\
\left.\text { frente à realidade (EA } A_{\mathrm{CCR}}\right) \text {. } \\
\text { - Pensamento do simples para o complexo, } \\
\text { crítico e sistêmico, incorporando aspectos da } \\
\text { ética, valores e emoções. } \\
\text { - Reconhecimento do tema socioambiental } \\
\text { enquanto complexo (vinculado ao âmbito } \\
\text { científico, social, econômico, político etc.). } \\
\text { - Complexificação que incorpora a } \\
\text { contextualização enquanto preocupação com a } \\
\text { dimensão espacial (local-global) e a dimensão } \\
\text { temporal (passado, presente e futuro). }\end{array}$ \\
\hline DEA & $\begin{array}{l}\text { Como estabelecer estudos de temas mais } \\
\text { abertos e dinâmicos em sala de aula? } \\
\text { Esses temas têm relação com a realidade } \\
\text { das(os) estudantes? Essa realidade é local } \\
\text { ou global? Quais conceitos e conteúdos } \\
\text { contemplar? Considerar o currículo } \\
\text { tradicional, trabalhando com enxertos, ou } \\
\text { alterar a organização curricular? Quais os } \\
\text { objetivos e as estratégias a serem } \\
\text { adotados nas aulas, de forma a estimular a } \\
\text { participação dos(as) estudantes? }\end{array}$ & $\begin{array}{l}\text { - Foco nos temas abertos, dinâmicos e } \\
\text { complexos, como os socioambientais. } \\
\text { - Reconhecimento do conhecimento escolar } \\
\text { autônomo, dinâmico e complexo. } \\
\text { - Complexificação do conhecimento cotidiano. } \\
\text { - Estratégias que respeitem as escolhas } \\
\text { docentes e o processo de aprendizagem da(o) } \\
\text { estudante (p. e., percursos temáticos, hipóteses } \\
\text { de transição e progressão, redução temática). }\end{array}$ \\
\hline DEp & $\begin{array}{l}\text { Qual a perspectiva da ciência mais } \\
\text { adequada para tratar questões de natureza } \\
\text { aberta e dinâmica, tais como as } \\
\text { socioambientais? Em que espaços as }\end{array}$ & $\begin{array}{l}\text { - Conhecimentos científicos escolares de } \\
\text { natureza dinâmica e complexa que permita } \\
\text { contemplar o acaso, o caos e a ordem- } \\
\text { desordem, as conexões, inter-relações, }\end{array}$ \\
\hline
\end{tabular}




\begin{tabular}{|l|l|l|}
\hline $\begin{array}{l}\text { distintas perspectivas de ciência } \\
\text { determinação, da indeterminação e da } \\
\text { complexidade) podem ser aplicadas? }\end{array}$ & $\begin{array}{l}\text { incertezas, riscos, os conceitos de flecha do } \\
\text { tempo, os acontecimentos e o papel do acaso, } \\
\text { além da irreversibilidade sob a perspectiva da } \\
\text { entropia. }\end{array}$ \\
& $\begin{array}{l}\text { - Vida estudada a partir das dinâmicas que } \\
\text { envolvem sistemas abertos, dissipativos, } \\
\text { desordem para gerar ordem, tempo limitante e } \\
\text { construtivo, limite dos sistemas vivos e ciclo } \\
\text { da vida. }\end{array}$ \\
\hline
\end{tabular}

A título de exemplificar o uso dessas Dimensões voltadas à complexidade na escola, é possível pensar nas ênfases (WATANABE, 2014) como aportes orientadores do trabalho docente. As ênfases sistematizam novas abordagens para os conceitos científicos escolares, buscando a representação da ciência como um conhecimento aberto e em contínua transformação e construção. Elas permitem uma articulação entre as esferas do conhecimento, acrescentando novas dimensões às escolhas que se fazem necessárias na elaboração de propostas de ensino, visando ao que chamamos de $\mathrm{EA}_{\mathrm{CCR}}$. Em nossas pesquisas foram identificadas as ênfases dinâmica, temporal, entrópica e das inter-relações. Por exemplo, na ênfase entrópica, a complexidade ganha papel destaque devido, principalmente, a natureza do problema a se tratado, ou seja, do próprio conceito de entropia. Nesse sentido, ao discutir a impossibilidade de um sistema retornar ao seu estado inicial, com as mesmas características originárias, implica trazer à tona os processos e limitações que impedem essa volta ao passado. Em outras palavras, a ênfase entrópica no contexto da complexidade implica explicitar que tudo tem uma história e essa história é irreversível. Isso leva ao entendimento de que é impossível voltar no tempo, retornando ao mundo primitivo, pois esse mundo não se reproduzirá. A vida, nesse contexto, trata-se de um conjunto de construções locais antientrópicas, que se mantém às custas de fluxos de energia, e que requerem um aumento da entropia do ambiente. A evolução das espécies e dos seres implica considerar que as relações que se estabelecem sempre produzem um novo panorama, em contínua transformação, ainda que constituídos pelas mesmas matérias e formas. Quanto às intervenções humanas na natureza, elas sempre aumentam a entropia, o que implica em desgaste permanente e, por isso, não se trata apenas de economizar energia, que estará sempre disponível, de uma forma ou de outra, mas de "economizar o desgaste" ou de economizar aumento de entropia. Sob essa perspectiva, podemos considerar que todo processo de reciclagem é limitado e impõe novos processos. Dessa forma, o importante é dimensionar e acompanhar a energia, assim como a capacidade de regeneração, dentro dos limites e possibilidades dos sistemas. 


\section{Estratégias metodológicas}

Para a produção deste artigo, as Dimensões foram tomadas como elementos orientadores da análise das produções. A seleção dos trabalhos mais recentes para análise, que tratam da complexidade no contexto do ensino e educação, foi realizada em dois momentos distintos: (i) em pesquisa de pós doutorado realizada na Espanha (de uma das autoras deste artigo), refletida parcialmente no artigo (WATANABE; RODRÍGUEZ-MARÍN, 2018), em que se buscou autores brasileiros ${ }^{5}$ e espanhóis mais próximos da perspectiva da complexidade enquanto elemento organizador de suas atividades educacionais, considerando o período de 2007 a 2016; e (ii) em pesquisa que buscou a publicação dos grupos identificados em (i), mas no período de 2017, visando exclusivamente a atualizar os dados da pesquisa anterior, .

A pesquisa foi realizada em revistas qualificadas pela WebQualis em ensino ${ }^{6}$. Optouse pelas revistas estratificadas em A1 e A2 ${ }^{7}$, com exceção da revista Alambique (B1) que foi selecionada por conta da publicação de grupos de pesquisa de referência com enfoque na sala de aula e devido ao interesse na revista pelos pesquisadores espanhóis. As revistas analisadas foram: Enseñanza de las Ciencias; Revista Eureka sobre Enseñanza y Divulgación de las Ciencias; Alambique; Investigación en la Escuela; Revista Brasileira de Pesquisa em Educação em Ciências (RBPEC); Ciência \& Educação; Investigações em Ensino de Ciências (IENCI); e Alexandria: Revista de Educação em Ciência e Tecnologia.

Para a seleção dos artigos em (i), buscou-se as palavras-chaves: educación medio ambiental (educación ambiental); medio ambiente; sostenibilidad (educación para la sostenibilidad); cambio climático; e contaminación, para produções espanholas; e educação (socio)ambiental; ambiente; sustentabilidade; mudanças climáticas; e contaminação, para as produções brasileiras. A opção por essas palavras se dá devido à possibilidade de tratar questões socioambientais abertas e complexas. Em seguida, foram analisados os resumos e texto completos procurando identificar a palavra complexidade, considerando-a enquanto uma perspectiva que fundamenta a ação educativa. Dessa busca foram identificadas as produções dos grupos IRES e Còmplex, de forma que para (ii) tomou-se como atualização os trabalhos desses grupos, apresentados no evento $10^{\mathrm{a}}$ Edición del Congreso Internacional sobre Investigación en la Didáctica de las Ciencias (2017).

O Quadro 2 traz as onze produções analisadas, considerando: T (Trabalhos), Revistas, Ano (de publicação), Título do artigo e seus respectivos grupos.

\footnotetext{
${ }^{5}$ Salienta-se que os autores brasileiros mais próximos da complexidade nessa linha não foram incorporados aqui visto que fazem parte da autoria deste artigo.

${ }^{6}<$ https://sucupira.capes.gov.br/sucupira/public/consultas/coleta/veiculoPublicacaoQualis/listaConsultaGeralPeri odicos.jsf $>$.

${ }^{7}$ Classificadas no quadriênio 2013-2016.
} 
Quadro 2 - Produções analisadas dos autores envolvidos com os grupos IRES e Còmplex.

\begin{tabular}{|c|c|c|c|c|}
\hline $\mathbf{T}$ & Revista & Ano & Título do artigo & Grupos \\
\hline $\mathrm{T} 1$ & $\begin{array}{l}\text { Enseñanza de las } \\
\text { ciencias }\end{array}$ & 2014 & $\begin{array}{c}\text { Competencias profesionales en educación para } \\
\text { la sostenibilidad: un estudio exploratorio de la } \\
\text { visión de futuros maestros }\end{array}$ & Còmplex \\
\hline $\mathrm{T} 2$ & $\begin{array}{l}\text { Enseñanza de las } \\
\text { ciencias }\end{array}$ & 2014 & $\begin{array}{c}\text { Las hipótesis de transición como herramienta } \\
\text { didáctica para la educación ambiental }\end{array}$ & IRES \\
\hline $\mathrm{T} 3$ & $\begin{array}{l}\text { Eureka Enseñ. Divul. } \\
\text { Cien. }\end{array}$ & 2010 & $\begin{array}{c}\text { Educación para la sostenibilidad desde la } \\
\text { perspectiva de la complejidad }\end{array}$ & Còmplex \\
\hline $\mathrm{T} 4$ & $\begin{array}{l}\text { Investigación en la } \\
\text { escuela }\end{array}$ & 2015 & $\begin{array}{l}\text { El huerto escolar ecológico como herramienta } \\
\text { para la educación en y para el decrecimiento }\end{array}$ & IRES \\
\hline T5 & $\begin{array}{l}\text { Investigación en la } \\
\text { escuela }\end{array}$ & 2007 & Investigando el problema del uso de la energía & IRES \\
\hline T6 & $\begin{array}{l}\text { Investigación en la } \\
\text { escuela }\end{array}$ & 2007 & $\begin{array}{c}\text { ¿Son incompatibles la escuela y las nuevas } \\
\text { pautas culturales? }\end{array}$ & IRES \\
\hline $\mathrm{T} 7$ & $\begin{array}{l}\text { Investigación en la } \\
\text { escuela }\end{array}$ & 2009 & $\begin{array}{c}\text { El activismo que no cesa. Obstáculos para } \\
\text { incorporar la metodología didáctica basada en } \\
\text { la investigación del alumno a la práctica de la } \\
\text { Educación Ambiental }\end{array}$ & IRES \\
\hline $\mathrm{T} 8$ & $\begin{array}{c}\text { Enseñanza de las } \\
\text { ciencias }(X \\
\text { Congreso) }\end{array}$ & 2017 & $\begin{array}{c}\text { Competencias profesionales en educación para } \\
\text { la sostenibilidad desde la complejidad }\end{array}$ & Còmplex \\
\hline T9 & $\begin{array}{c}\text { Enseñanza de las } \\
\text { ciencias }(X \\
\text { Congreso) }\end{array}$ & 2017 & $\begin{array}{c}\text { Análisis de un modelo formativo para avanzar } \\
\text { en la ambientalización curricular: } \\
\text { transferencia en diversidad de contextos }\end{array}$ & Còmplex \\
\hline $\mathrm{T} 10$ & $\begin{array}{c}\text { Enseñanza de las } \\
\text { ciencias }(X \\
\text { Congreso) }\end{array}$ & 2017 & $\begin{array}{l}\text { Menos es más (complejidad). Una reflexión } \\
\text { sobre la concepción de complejidad } \\
\text { predominante en el pensamiento decrecentista }\end{array}$ & IRES \\
\hline $\mathrm{T} 11$ & $\begin{array}{c}\text { Enseñanza de las } \\
\text { ciencias }(X \\
\text { Congreso) }\end{array}$ & 2017 & $\begin{array}{l}\text { Los huertos escolares ecológicos, un camino } \\
\text { decrecentista hacia un mundo más justo }\end{array}$ & IRES \\
\hline
\end{tabular}

As informações desses artigos foram obtidas seguindo as ações: a) localização dos referenciais e produções que tratam da complexidade; e b) leitura na íntegra dos textos selecionados. As informações desse mapeamento foram analisadas por meio da Análise Textual Discursiva (MORAES; GALIAZZI, 2007), seguindo as etapas: unitarização realização da fragmentação de trechos dos estudos que fazem referência implícita ou explícita a elementos que apresentam relação com as Dimensões da complexidade, emergindo assim, unidades de significado; identificação de categorias temáticas - agrupamento das unidades de significado segundo suas semelhanças semânticas; comunicação - elaboração de textos descritivos e interpretativos (metatextos), acerca das categorias temáticas. 
IV. Os resultados encontrados: identificação das Dimensões como elementos organizadores da perspectiva da complexidade para uma educação científica escolar

Os artigos do IRES e do Còmplex que trazem elementos da complexidade como aspecto fundamental na formação científica escolar são analisados a fim de identificar em que medida é possível associar as suas propostas às Dimensões por nós caracterizadas. Apresentamos, a seguir, a síntese da análise de cada um dos artigos, para, em seguida, buscar uma abordagem de seu conjunto.

\section{T1 - Competencias profesionales en educación para la sostenibilidad: un estudio exploratorio de la visión de futuros maestros (2014)}

Investiga quais seriam algumas das competências profissionais a serem desenvolvidas pelos professores visando a uma educação para sustentabilidade. No conjunto de suas considerações fica explícita que a preocupação central é com a DE. Em especial, ao buscar "adotar um modelo centrado no aluno e em sua aprendizagem em que promova de maneira ativa o pensamento crítico, a contextualização, a ação e coesão social (...), uma educação para a transformação social sustentável, que estimula a reflexão crítica e a clarificação de valores, promove o pensamento sistêmico e é inovadora e construtiva" (T1, p. 30, 2014). Na medida em que o conceito de competência, para os autores, é central, e em função do seu próprio entendimento sobre competência, DEA e DE se articulam ou se sobrepõem com muita coerência. Nas diversas competências que sistematiza, comparecem aspectos de ambas essas Dimensões. Ainda assim, parece que, na maioria das vezes, se explicitam mais claramente as dimensões formativas a serem consideradas, e não tanto o processo de aprendizagem envolvendo o aluno. Isso se expressa pela preocupação com que estejam envolvidas na aprendizagem ética, valores e ação. No momento em que apontam para o paradigma da complexidade como uma das bases que caracterizam o estudo, é possível identificar a DEp. Comparecem alguns aspectos, ainda que às vezes de forma indireta. Defende, por exemplo, "um enfoque holístico e integrador, que identifique mudanças e aponte transformações" (T1, p. 33, 2014). Da mesma forma, destaca a necessidade de "integrar a complexidade como paradigma interpretativo da realidade e do pensamento" (T1, p. 35, 2014). Traz, também, aspectos da DEA ao estabelecer diálogo com as disciplinas e ao deixar evidente que o trabalho pode orientar pesquisa futuras que busquem outras estratégias educativas e instrumentos avaliativos para uma integração da sustentabilidade com a formação docente, ainda que como projeto futuro.

\section{T2 - Las hipótesis de transición como herramienta didáctica para la educación ambiental (2014)}

Apresenta uma reflexão detida acerca do conceito hipóteses de transição. A estreita relação entre as Dimensões aparece logo de partida, ao salientar que o trabalho se refere a um 
estudo "dos aspectos teóricos e práticos relacionados com as hipóteses de transição dentro do âmbito da Educação Ambiental" (T2, p. 303, 2014). Trata-se de discutir as hipóteses de transição como ferramentas didáticas, que seriam um instrumento para dar sentido, para aquele que ensina, ao processo de construção do conhecimento. Essas transições se tornam imperativas e passam a fazer sentido a partir do paradigma da complexidade, correspondendo à necessidade de propor uma gradação da passagem do simples ao complexo, tanto nos conteúdos como na reformulação dos problemas a serem investigados. Centrada na questão do ensino aprendizagem (DEA), é expressão de uma proposta de educação ambiental, que não pode prescindir do complexo. Assim, as transições propostas dizem respeito a passar a considerar uma concepção ecossistêmica, relativista e integradora, superando a causalidade linear em nome de uma causalidade complexa (DEp). Ao longo do texto ganha destaque a preocupação com uma educação que dê relevância aos aspectos sócio-construtivistas e considere perspectiva do aprendiz, seus interesses e sua motivação canalizados através das emoções. Tais aspectos caracterizam a DE. Destaca-se o paradigma da complexidade que “supõe mudar a nossa concepção de própria investigação didática: uma análise processual da evolução das ideias de um grupo de alunos e alunas desde o simples ao complexo, relacionado a um conteúdo marcado pela integração de conhecimentos de natureza diferente, e num contexto sistêmico e complexo como é a aula (entendido como espaço donde se desenvolve o processo de ensino-aprendizagem)" (T2, p. 305, 2014), o que nos remete à DEp.

\section{T3 - Educación para la sostenibilidad desde la perspectiva de la complejidad (2010)}

Incorpora reflexões acerca de uma mudança na forma de pensar a educação, apontando que a crise que vivemos e colocando em evidência a complexidade. Tal crise aparece em três vertentes, simultaneamente: uma crise socioambiental, uma de valores e outra de conhecimento. Aponta que um modelo educativo deve ser aberto, dinâmico, que capacite os sujeitos a atuar, que seja capaz de estabelecer diálogos. O caráter epistêmico vai aparecer explicitamente ao tratar da forma de se entender o mundo, que demanda a complexidade. Nesse sentido, os princípios para aproximar-se dos fenômenos incluem o caráter sistêmico, a abordagem dialógica, em que diferentes perspectivas não se excluem, mas se explicam de forma recíproca e dinâmica, e o hologramático, que diz respeito à relação entre o todo e as partes. Tais aspectos evidenciam características da DEp. Ao salientar que seria "interessante elaborar propostas considerando que o objeto de estudo é um ponto de confluência da diversidade de interesses, que cada uma das propostas de aula são uma entre muitas e que estas podem entrar em contradição com os interesses de outros coletivos” (T3, p. 209, 2010) ganham espaço também aspectos da DEA. Ao tratar da educação ambiental como um espaço para buscar modelos de pensamento que estimula a criatividade, imaginação, emoção, sentimento, intuição, desordem e liberdade etc. ganham espaço aspectos da DE. Assim, destaca a importância de "construir livremente estratégias, reconhecendo limites, utilizando as 
regras que permitem ativar a criatividade que é racional e também intuitiva, integradora de pensamento e sentimento" (T3, p. 209, 2010).

\section{T4 - El huerto escolar ecológico como herramienta para la educación en y para el decrecimiento (2015)}

Discute o cultivo das hortas escolares e sociais como meio de promover uma educação com foco nos conceitos de decrescimento e permacultura. Ao tratar dos aspectos da implementação das hortas na escola e em uma comunidade local, destacam as questões e conceitos que foram tratados assim como analisam os resultados obtidos nessas intervenções e suas limitações. Destacam os conteúdos conceituais, procedimentais e os valores presentes nas propostas desenvolvidas (DEA). Ao tratar dessas atividades explicitam a proposta educacional implícita (DE). Salienta a necessidade de discutir o termo sustentabilidade e defende que "devemos pensar em educar as pessoas para se adaptarem a um mundo com menos recursos e que essa adaptação não seja caótica, mas ordenada e justa" (T4, p.39, 2015). A DEp, como também pode ser vista no trecho destacado, volta-se à complexidade enquanto referência para uma educação ambiental na perspectiva integradora.

\section{T5 - Investigando el problema del uso de la energía (2007)}

Exemplifica uma abordagem do tema energia a partir da metodologia didática baseada na investigação do aluno e no tratamento de problemas abertos. Há uma preocupação direta com o quê e como tratar o tema em sala de aula (DEA), destacando a contribuição da complexidade para responder à necessidade de passar do simples ao complexo. Toma para isso a temática Ecologia com foco no desenvolvimento de um pensamento mais complexo. Discute a complexificação do conhecimento cotidiano a partir da necessidade de integrar "os aspectos naturais com os sociais, evitando os pensamentos reducionistas"; "a ciência com os valores e as atitudes (as ideologias)"; "os diferentes tipos de conhecimentos (conceitual, procedimental e atitudinal) entre si e com a ação"; e "o local com o global, o concreto com o geral". Ainda que para essa reflexão destaca-se muita preocupação com a DEA, tal como ocorreu com os artigos anteriores do IRES, os autores apresentam relações mais ou menos intensas com as DE e DEp. Nesse caso há de se considerar, por exemplo, a preocupação em superar as visões egocêntricas, sociocêntricas e antropocêntricas dos sujeitos, e a perspectiva do antagonismo, em prol da complementariedade (negociação democrática, argumentação fundamentada e busca do consenso na tomada de decisões e na resolução de conflitos).

\section{T6 - ¿Son incompatibles la escuela y las nuevas pautas culturales? (2007)}

Discute com certa profundidade aspectos da cultura que, de seu ponto de vista, se define por um pensamento único. Isso caracteriza fortemente a DE. Para T6, o "O individualismo consumista, o mercado e a globalização econômica são grandes eixos sobre os 
que se organiza a sociedade atual, predominando sobre as instituições tradicionais (estado, partidos políticos, sindicatos...)" (T6, p.19, 2007). Traz ainda distintas críticas ao modelo atual defendendo a complexidade como um paradigma necessário para lidar com a sociedade atual; em especial, salienta que "se trivializa o complexo: tudo agora é light, desde a democracia a ecologia até o ecodesenvolvimento" (T6, p.21, 2007).

\section{T7 - El activismo que no cesa. Obstáculos para incorporar la metodología didáctica basada en la investigación del alumno a la práctica de la Educación Ambiental (2009)}

Discute o modelo ativista presente na prática de professores espanhóis e busca, a partir disso, refletir sobre uma experiência acerca de ações escolares com foco numa perspectiva integradora, dando enfoque para DEA. Ao discutir a perspectiva integradora aponta para uma intervenção escolar pautada pelo construtivismo, a epistemologia da complexidade e a perspectiva crítica, o que leva, ainda que com menor atenção explícita, aos aspectos que caracterizam a DEp. Ou ao apontar para a necessidade de uma intervenção pautada num processo teórico-prático e de reflexão-ação, recorrente, gradual e progressivo.

\section{T8 - Competencias profesionales en educación para la sostenibilidad desde la complejidad (2017)}

Trata dos domínios de competência em educação para a sustentabilidade que discute "(...) uma maneira de pensar; uma maneira de conviver; uma maneira de sentir; e uma maneira de atuar". Como exemplo, aparece a preocupação em que "o indivíduo assuma a liberdade como responsabilidade, a convivência como modelo para avançar a democracia e a ação como veículo de transformação social, ambiental e econômica" (T8, p.4876, 2017). Esses aspectos apontam para a DE. Trata, também, do marco de competências profissionais na perspectiva da complexidade, apontando para: conexões, diálogo, criatividade, inovação, pensamento crítico e incertezas; aspectos que caracterizam a DEp. A DEA aparece sutilmente ao apontar a opção metodológica da aula, que se refere ao marco teórico de investigação, considerando a importância de nível profissional dos processos de ensino-aprendizagem.

\section{T9 - Análisis de un modelo formativo para avanzar en la ambientalización curricular: transferencia en diversidad de contextos (2017)}

Discute uma proposta de modelo formativo, o que denota preocupação com a DEA. Especificamente, procura abordar a educação para o consumo por meio de uma investigação permanente que levará às ações em sala de aula. Para a proposta, analisam a gravação de áudio de uma sessão formativa e entrevistas durante e depois dessas sessões. As reflexões que permeiam o artigo apontam também para aspectos da DE ao, por exemplo, salientar que "a ambientação curricular comporta trabalhar e adquirir competências do pensamento complexo e global em relação ao meio e, ao mesmo tempo, fomentar a responsabilidade, o compromisso 
e a ação da comunidade educativa para o desenvolvimento de sua identidade ambiental" (T09, p.3138, 2017). De forma semelhante, a DEp aparece ao justificar em diversos momentos que "a complexidade se configura como uma plataforma rigorosa, aberta e dinâmica que pode ajudar a abordar o contexto de crise global de uma forma criativa e transformadora" (T09, p. 3138, 2017).

\section{T10 - Menos es más (complejidad). Una reflexión sobre la concepción de complejidad predominante en el pensamiento decrecentista (2017)}

Discute a questão do decrescimento e aspectos da complexidade. A preocupação central está em "revalorizar a ciência e tecnologia em uma sociedade em decrescimento" (T10, p. 4867, 2017), conferindo centralidade à perspectiva epistemológica (DEp). São contrapostas duas perspectivas, ambas relacionadas com diferentes compreensões da complexidade. De acordo com uma delas, o decrescimento supõe uma descomplexificação do sistema social. Pela outra, ao contrário, impõe uma compreensão mais profunda do que seja o complexo, para além de aspectos quantitativos. Não significa apenas reduzir a produção de bens, mas incluir a compreensão dos aspectos pelos quais que essa redução interfere na organização social. Nessa compreensão, os aspectos da construção do conhecimento complexo ganham um destaque especial. Introduz alguns exemplos, relacionados ao consumo, energia, agricultura, monocultivo, dentre outros, para apresentar os sistemas complexos abertos, em reorganização contínua, em que estão presentes interações envolvendo três fatores: matéria, energia e informação. Dessa perspectiva decorre "que o conhecimento não pode ser entendido como uma acumulação de dados, mas como a construção de um sistema de idéias com diferentes formas de organização" (T10, p. 4868, 2017). Com menos profundidade, aparece a discussão acerca da permacultura como um exemplo para lidar com as questões do decrescimento, apontando para a DEA; com a preocupação em propor uma "educação baseada na aprendizagem significativa, na investigação de problemas, na criatividade, no espírito crítico, no pensamento complexo (ao modo de Edgar Morin), no conhecimento científico e no trabalho cooperativo" (T10, p. 4870, 2017) a fim de sermos mais resilientes. Em termos de perspectiva educacional (DE), é muito explícito, embora também não seja seu foco. Questiona-se o sistema educativo hierarquizado e centralizado em pensamentos únicos, contrapondo a ele um sistema mais complexo, baseado na autonomia, criatividade e espírito crítico.

\section{T11 - Los huertos escolares ecológicos, un camino decrecentista hacia un mundo más justo (2017)}

Discute as hortas escolares como uma forma de tratar os conceitos pautados também na ideia de decrescimento. Esses aspectos pressupõem a identificação de fatores limitantes, associados aos nutrientes do solo, à água, à luz e temperatura, dentro de um quadro mais geral dos limites biofísicos em um contexto de esgotamento de recursos e mudança climática. 
Dessa forma, contrapõe a complexificação ao decrescimento. Ao buscar contextualizar o aporte desses conhecimentos em uma atividade didática, traz uma perspectiva concretizada em ações cotidianas, reconhecidas como ferramentas didáticas (DEA). Salienta que "as hortas escolares são uma ferramenta didática utilizada há décadas, tendo demonstrado sua potencialidade para promover a aprendizagem de conteúdos escolares" (T11, p. 805, 2017). Destaca que a proposta da horta vai além de um "recurso didático de apoio às atividades docentes cotidianas, convertendo-a em um eixo organizador de toda atividade eco-escolar e em um núcleo para o incremento da resiliência das futuras gerações (a horta ecológica como recursos para a sobrevivência)" (T11, p. 809, 2017). Com isso, busca associar à escola outras dimensões que não apenas a dos conteúdos escolares tradicionais, com ênfases meramente cognitivas. A partir dessas considerações, é possível notar que há referência às DE e DEp. De forma implícita, a complexificação parece emergir do reconhecimento dos diversos subsistemas envolvidos (DEp), assim como da interações entre esses sistemas e a evolução em aberto dos problemas. Destaca que a educação deveria permitir a tomada de consciência da real situação em que vivemos e pautada em estratégias para viver com menos recursos sem que isto suponha entrar em uma condição de caos e desordem, apontando aspectos da DE. Há, novamente, a relação complexidade e decrescimento, onde ganham destaque as ideias acerca do decrescimento enquanto uma corrente de pensamento social, econômico e ambiental com foco na redução da produção.

A análise dos artigos acima indica que as abordagens da questão da complexidade são múltiplas e diferenciadas. Em cada caso, foi possível identificar dimensões privilegiadas, segundo nossa proposta inicial, algumas vezes de forma articulada. Essas constatações apontam, também, em decorrência, que uma aproximação mais abrangente desse conjunto pode trazer novas contribuições.

Para isso, os resultados das análises foram reunidos no Quadro 3. Nele, estão indicadas as Dimensões (DE, DEA e Dep) encontradas nos onze artigos, dando destaque àquelas que mais se acentuam nos discursos de cada autor. Assim, a célula com um $\mathbf{X}$ (em negrito) indica a Dimensão mais intensa no artigo, ou a abordagem privilegiada dentro dos objetivos específicos dos autores, no contexto educacional por eles tratado. Isso não significa que outras dimensões não estejam contempladas ou não explicitadas. Nessa direção, a célula com um * indica a presença da Dimensão, ainda que sem destaque explícito.

Quadro 3 - As Dimensões presentes nos artigos analisados.

\begin{tabular}{|c|c|c|c|c|c|c|c|c|c|c|c|}
\hline & $\mathrm{T} 1$ & $\mathrm{~T} 2$ & $\mathrm{~T} 3$ & $\mathrm{~T} 4$ & $\mathrm{~T} 5$ & $\mathrm{~T} 6$ & $\mathrm{~T} 7$ & $\mathrm{~T} 8$ & $\mathrm{~T} 9$ & $\mathrm{~T} 10$ & $\mathrm{~T} 11$ \\
\hline $\mathbf{D E}$ & $\mathbf{X}$ & $*$ & $\mathbf{X}$ & $\mathbf{X}$ & $*$ & $\mathbf{X}$ & $*$ & $\mathbf{X}$ & $*$ & $*$ & $*$ \\
\hline $\mathbf{D E A}$ & $*$ & $\mathbf{X}$ & $*$ & $\mathbf{X}$ & $\mathbf{X}$ & $*$ & $\mathbf{X}$ & $*$ & $\mathbf{X}$ & $*$ & $\mathbf{X}$ \\
\hline $\mathbf{D E p}$ & $*$ & $*$ & $\mathbf{X}$ & $*$ & $*$ & $*$ & $*$ & $\mathbf{X}$ & $*$ & $\mathbf{X}$ & $*$ \\
\hline
\end{tabular}


Devido aos distintos focos delineados em cada artigo, é possível identificar a dimensão privilegiada. Trata-se, portanto, do interesse daquela pesquisa no momento da publicação específica analisada. Ou seja, isso não reflete as trajetórias de pesquisa e os interesses gerais desses(as) autores(as), que podem ser mais abrangentes. Isso é bastante coerente com os resultados esperados, visto que as dinâmicas de estudo e de visão de mundo dos autores estão em construção permanente.

Em uma primeira aproximação, é interessante observar que prevalecem as preocupações relacionadas à DEA (6 artigos) e DE (5 artigos), sendo menos frequente a dimensão propriamente epistemológica DEp (3 artigos). De uma maneira geral, as articulações estão sempre presentes, ainda que não apresentem iguais focos de atenção. Chama atenção a articulação entre DE e DEp.

No que diz respeito à $\mathrm{DE}$ (presentes em T1, T3, T4, T6 e T8), esses trabalhos privilegiam a complexidade associada a uma educação para a sustentabilidade, o que implica tratar uma educação para a transformação social, crítica em relação à sociedade consumista e sua organização, reconhecendo-a como uma sociedade em crise. Ainda que apontando para o decrescimento, contrapõe-se a ele como descomplexificação. É possível identificar a aproximação à complexidade através da necessidade do pensamento sistêmico, incorporando ética, valores e ação, além de criatividade e emoção às propostas educacionais.

Propostas de concretização de ações de ensino aprendizagem são contempladas na DEA (presentes em T2, T4, T5, T7, T9 e T11), seja reconhecendo o processo de passagem dos sistemas simples aos complexos, seja integrando aspectos locais com indicações gerais/ globais. A organização das atividades privilegia a investigação dos estudantes, como investigação permanente, envolvendo problemas abertos e dinâmicos.

Os aspectos relacionados à DEp (presentes em T3, T8 e T10), presentes com diferentes ênfases, remetem a considerações de sistemas abertos, em reorganização contínua, contemplando matéria, energia e informação como elementos não quantitativos mas organizacionais. Nesse sentido, se privilegiam ênfases sistêmicas, dialógicas e considerações sobre o todo/ partes, com uma caracterização importante da complexidade, reiterando sua importância em relação ao decrescimento.

\section{Aproximações e distanciamentos dos grupos espanhóis frente às Dimensões}

Diante dos resultados presentes no Quadro 3, é interessante buscar aproximações e diferenças entre o tratamento da questão da complexidade na educação em ciências, considerando as perspectivas de trabalho de grupos estudados - IRES e Còmplex - e das Dimensões de análise indicadas pelos estudos do grupo brasileiro. Pretende-se que os eventuais pontos e contrapontos tenham potencial para enriquecer o debate acerca da complexidade no âmbito do ensino e da educação.

Um primeiro apontamento acerca dos resultados, que tomamos como um alerta ao analisá-los, leva-nos às diferenças de contextos. Ou seja, para interpretar os resultados há de 
se considerar que a escola e os(as) estudantes brasileiros(as) têm características peculiares frente ao público espanhol. Isso vai desde o formato do sistema educativo, influenciado pelas políticas públicas dos países envolvidos, até os contextos culturais que se traduzem na cultura primeira, ou no conhecimento cotidiano, dos(as) alunos(as). Nesse sentido, a partir dos dados obtidos nos artigos, podemos identificar apenas algumas características da abordagem da complexidade que podem ser consideradas em uma formação educacional mais abrangente e global. Assim, a reflexão realizada busca salientar aspectos mais gerais da complexidade que podem subsidiar um ensino mais crítico em distintas realidades procurando, sempre que possível, apontar para as peculiaridades que devem ser consideradas devido aos contextos locais das produções.

Pautada por essa consideração, o que chama atenção nessa abordagem é a persistência de algumas características da complexidade, independentemente do contexto, especificamente considerando as perspectivas das Dimensões. Ou seja, ainda que as diferenças de nacionalidades sejam elementos fundamentais de análise, os aspectos identificados na literatura partindo das características das Dimensões, inicialmente resultado de pesquisa brasileira, também aparecem nas produções espanholas.

Nesse sentido, chama atenção a convergência em propósitos e meios, especialmente considerando que as pesquisas vêm sendo desenvolvidos de forma relativamente independente. Por exemplo, os parâmetros mais gerais, como a busca por uma educação mais crítica e reconhecimento do conhecimento escolar autônomo, dinâmico e complexo, são aspectos muito presentes nos discursos dos dois países, assim como a preocupação com temas abertos, dinâmicos e complexos, como os socioambientais. Especificamente, a questão da preocupação com uma sociedade de riscos, está mais explicitamente presente na abordagem brasileira.

No entanto, há também diferenças que podem contribuir para o enriquecimento de ambas as realidades. Assim, a busca por incorporar aspectos relacionados à ética, valores e emoções é assunto explicitado em quase todos os trabalhos do Còmplex. Igual atenção, ou pelo menos com igual ênfase, não está tão presentes explicitamente nas Dimensões do grupo brasileiro. Esse destaque, no contexto da complexidade, é importante, na medida em que podem ser chaves de articulação entre as três dimensões, para além do conhecimento escolar propriamente dito.

Da mesma forma, a influência da realidade dos sujeitos aponta para diferentes ênfases. No quadro espanhol, a questão do decrescimento é um dos elementos centrais, como parte de um debate social mais geral. Embora a crítica ao consumismo seja também partilhada no cenário brasileiro, essa aproximação se dá por uma crítica ao desenvolvimento pautada por outros fatores, especialmente como espaço de lutas sociais. Essa, talvez, seja uma influência direta das propostas educacionais de Paulo Freire, presentes fortemente na educação brasileira. É possível identificar tal diferença, ainda que os grupos espanhóis também reconheçam a contribuição freireana, na medida em que o fazem com destaques diferentes. 
No contexto específico do IRES (Grupo de Sevilha), embora Paulo Freire não seja explicitado em seus referenciais, toma-se como elemento organizador o conhecimento cotidiano, enquanto tarefas e aprendizagens a serem realizadas no dia a dia. No Còmplex (Grupo de Barcelona), a perspectiva freireana é trazida como um dos aspectos que fundamentam a sua teoria, para além das ações educativas. Essas ações são, no universo brasileiro, justamente as possibilidade de intervenções sociais.

Ao estudar a presença da perspectiva da complexidade nas produções espanholas, tomando elementos que caracterizam a DE, DEA e DEp (tal como realizamos) foi possível identificá-las com maior ou menor ênfase em quase todos os artigos (ver Quadro 2). Isso demonstra que essas dimensões são preocupações, de fato, presentes e incorporadas naquele universo, ainda que não explicitadas como tal. Nesse sentido, parece- nos importante enfatizar as Dimensões como instrumentos de análise pertinentes, como formas de explicitar demarcações de naturezas diferentes, que permitem atribuir um sentido maior ao debate da complexificação.

Esse resultado indica, também, que ao se tratar de mudanças na forma de pensar a educação e a complexidade, é essencial que as propostas venham acompanhadas de um conjunto de ações pautadas simultaneamente nos pressupostos das três Dimensões. Ou seja, não é viável pensar em uma formação dessa natureza tomando apenas como referência uma delas. Por exemplo, não poderia ser proposta uma educação (DE) que contemple o pensamento complexo, sem que isso envolva também uma mudança de estratégia (DEA) e de perspectiva da ciência (DEp). Da mesma forma, iguais limitações ocorreriam com as outras Dimensões. Caso as Dimensões sejam tratadas separadamente, as abordagens passam a ser pontuais e pouco significativas, resultando em ações que levam à repetição de discursos sem efetiva mudança de postura.

Essa simultaneidade é particularmente relevante no que diz respeito às implicações relacionadas à dimensão epistemológica. Como vimos, a complexidade do ponto de vista físico, por exemplo, implica em um conjunto de pressupostos e desenvolvimentos que não são em geral abordados na escola básica, por diversas dificuldades. No entanto, tratar a complexidade vai além do aspecto cognitivo restrito, já que pode sinalizar inúmeros elementos e/ou compreensões de fenômenos físicos, que constituem o novo modo de abordagem dos problemas da complexidade. Ou seja, interessa identificar as características físicas desse novo paradigma, sem necessariamente seus aspectos específicos. E isso só é possível se coerente ou a serviço de uma proposta educacional, envolvendo a compreensão de novas dinâmicas de ensino e aprendizagem.

\section{Considerações para a ação}

Em suma, a pesquisa, ao mostrar que em maior ou menor grau o discurso da complexidade é tratado nas três Dimensões, nos leva a entender que para propor uma ação na perspectiva complexa há de se ter clareza sobre os objetivos da formação, a forma/ 
linguagem/ perspectiva da ciência a ser contemplada e as estratégias de abordagem com as quais o assunto será tratado. Disso tudo, nos parece claro que o foco está na possibilidade de dar à(ao) estudante a oportunidade de analisar o mundo sob uma perspectiva mais aberta, pautada em elementos que aproximem a ciência das questões que envolvem a realidade dos indivíduos. Essa realidade vai depender do contexto no qual os indivíduos estão submetidos, mas claramente há de trazer elementos que mobilizem ações para além dos muros da escola. No Brasil, essa realidade pode envolver problemas oriundos das condições de sobrevivência e insegurança reais; enquanto na região da Catalunha e Andaluzia, isso se reverte às questões de reciclagem, refugiados ou escassez de água potável. Nesses exemplos, a criticidade aparece como um elemento chave para dar oportunidade de se pensar as condições humanas de trabalho e sobrevivência em um contexto social, cultural e político muito adverso.

Vale destacar que a complexidade é uma linguagem/ perspectiva relativamente recente e que requer aprofundamentos para que seja levada efetivamente à escola. Isso acontece tanto aqui como na Espanha. Mas isso não significa deixá-la à margem da formação básica e mesmo universitária. É essencial que os sujeitos possam ter argumentos científicos escolares para se posicionar frente aos problemas que vivenciam em suas realidades, impostas por dinâmicas sociais adversas. E que o enfrentamento desses problemas requer uma abordagem complexa. Vale destacar que há trabalhos que avançaram muito nessa questão, e apresentam experiências interessantes no que se refere à complexidade no domínio da educação, de ensino-aprendizagem e epistemológico.

O contexto dessa reflexão exige, no entanto, uma sinalização importante e central. De certa forma, nos parece importante considerar que as Dimensões são "universais", ou seja, podem ser consideradas como dizendo respeito a qualquer tipo de ação ou proposta educacional. No entanto, a complexidade impõe uma articulação maior entre elas, de forma que é muito difícil separá-las. Essa é sua grande especificidade. As produções analisados mostram que em maior ou menor incidência as três Dimensões estão presentes. Nesse sentido, a complexidade não é um tema a ser incorporado, nem ênfases, mas uma forma de encarar e trabalhar mais significativa. Ela demanda uma visão de mundo que vai além das distintas complexidades estudadas (da Biologia, da Economia, da Física, da Matemática etc.); ela requer uma aproximação entre as Dimensões a fim de "naturalizar" as ações e reflexões pautadas pela criticidade.

Para nós, a perspectiva da complexidade pode ajudar a entender o mundo de forma mais realista implicando, por exemplo, em buscar soluções que levem em conta o decrescimento sem descomplexificar; de pensar em formas de organização social que compartilhem espaços mais eficientes tais como os colivings (espaços comunitários); que dê oportunidade para os sujeitos produzirem seus alimentos livres de agrotóxicos; que promova a consciência acerca dos riscos em espaços vulneráveis, etc. No último caso, deveríamos tratar os riscos e o princípio de precaução nas escolas para que os nossos alunos e alunas fossem 
capazes de discutir e refletir criticamente sobre os acontecimentos reais pautando-se também pelo conhecimento científico.

\section{Agradecimentos}

Essa pesquisa refere-se ao processo $n^{\circ}$ 2018/19136-3, da Fundação de Amparo à Pesquisa do Estado de São Paulo (FAPESP), a qual agradecemos o financiamento.

\section{Referências}

BECK, U. A reinvenção da política: rumo a uma teoria da modernização reflexiva. In: BECK, U; GIDDENS, A. E LASH, S. (Org). Modernização reflexiva. São Paulo: Editora da Unesp, 1997. p.11-72.

BECK, U. Sociedade de Risco. São Paulo: Editora 34, 2010.

BONIL J.; JUNYENT M.; PUJOL R. M. Educación para la sostenibilidad desde la perspectiva de la complejidad. Revista Eureka sobre Enseñanza y Divulgación de las Ciencias, v. 7, n. Extraordinario, p. 198-215, 2010.

CABAlleros, V.; PUBILl, M. J.; SUBIRÁ, G. C. Análisis de un modelo formativo para avanzar en la ambientalización curricular: transferencia en diversidad de contextos. Enseñanza de las ciencias (X Congreso), Espanha, n.extra, p. 3137-3142, 2017.

CASAL, L. M. La izquierda ante el colapso de la civilización industrial. Madrid: La Oveja Roja, 2016.

CINI, M. Un paradiso perduto. Itália: Editora Feltrinelli, 1994.

DELIZOICOV, D.; ANGOTTI, J. A.; PERnAMBUCO, M. M. Ensino de Ciências: fundamentos e métodos. São Paulo: Cortez, 2002.

FERNÁNDEZ, R.; GONZÁLEZ, L. En la espiral de la energía. Madrid: Libros en Acción. Baladre, 2014.

FERNÁNDEZ-ARROYO, J.; PUIG-GUTIÉRREZ, M.; DÍAZ, J. E. G. Menos es más (complejidad). Una reflexión sobre la concepción de complejidad predominante en el pensamiento decrecentista. Enseñanza de las ciencias (X Congreso), Espanha, n. extra, p. 2174-6486, 2017. 
DÍAZ, J. E. G.; GARCÍA, F. F.; MARTÍN, J.; PORLÁN, R. ¿Son incompatibles la escuela y las nuevas pautas culturales? Investigación en la escuela, Espanha, n. 63, p. 17-28, 2007.

DÍAZ, J. E. G.; RODRÍGUEZ-MARÍN, F.; SOLÍS, M. C.; BALLENILLA, F. Investigando el problema del uso de la energía. Investigación en la escuela, Espanha, p. 29-45, 2007.

FREIRE, P. Pedagogia da autonomia: saberes necessários à prática educativa. São Paulo: Paz e Terra, 2006.

FIELDLER-FERRARA, N. Ciência, ética e solidariedade. In: CARVALHO, E. A.; ALMEIDA, M. C.; COELHO, N. N.; MORIN, E. (Org.). Ética, solidariedade e complexidade. São Paulo: Palas Athena, 1998.

FIELDLER-FERRARA, N. O pensar complexo: construção de um novo paradigma. In: SIMPÓSIO NACIONAL DE ENSINO DE FÍSICA, XV, 2003, Curitiba. Atas...

GARCÍA, J. E. Hacia una teoría alternativa sobre los contenidos escolares. Espanha: Díada Editora S. L., 1998.

GARCÍA, J. E. Educación ambiental, constructivismo y complejidad. Série Fundamentos, n. 21. Espanha: Díada Editora S. L., 2004a.

GARCÍA, J. E. Los contenidos de la educación ambiental: una reflexíon desde la perspectiva de la complejidad. In: Investigación en la escuela. Espanha: Sevilla, n. 53, p. 31-51, 2004b.

GARCÍA, J. E.; WATANABE, G. Menos pode ser mais: do decrescimento e descomplexificação à complexidade. Revista Linhas Críticas, UnB, 2019.

CEBRIÁN, G.; PUBILL, M. J. Competencias profesionales en educación para la sostenibilidad: un estudio exploratorio de la visión de futuros maestros. Enseñanza de las ciencias, Espanha, p. 29-49, 2014.

GOULD, S. J. Revista Scientific American, Rio de Janeiro, p. 84-100, 1994.

GOULD, S. J. 'O que é vida?' Como um problema histórico. In: MURPHY E O'NEILL (Org.). O que é a vida? 50 anos depois. São Paulo: Editora UNESP, 1997.

LACEY, H. O princípio de precaução e a autonomia da ciência. Scientiæ Studia, São Paulo, v. 4, n. 3, p. 373-92, 2006. 
LATOUCHE, S. Pequeno tratado do decrescimento sereno. 1. ed. São Paulo: WMF Martins Fontes, 2009.

MARÍN, F. R.; ARROYO, J. F; DÍAZ, J. E. G. Los huertos escolares ecológicos, un camino decrecentista hacia un mundo más justo. Enseñanza de las ciencias (X Congreso), Espanha, n. extra, p.805-810, 2017.

MARÍN, F. R.; ARROYO, J. F; DÍAZ, J. E. G. El huerto escolar ecológico como herramienta para la educación en y para el decrecimiento. Investigación en la escuela, Espanha, p. 35-48, 2015.

MARÍN, F. R.; ARROYO, J. F; DÍAZ, J. E. G. Las hipótesis de transición como herramienta didáctica para la educación ambiental. Enseñanza de las ciencias, Espanha, p.310-318, 2014.

MARÍN, F. R.; DÍAZ, J. E. G. El activismo que no cesa. Obstáculos para incorporar la metodología didáctica basada en la investigación del alumno a la práctica de la Educación Ambiental. Investigación en la escuela, Espanha, n. 67, p. 23-36, 2009.

MORAES, R.; GALIAZZI, M. C. Análise Textual Discursiva. Ijuí: Editora Unijuí, 2007.

MORIN, E. Introdução ao pensamento complexo. 3. ed. Porto Alegre: Sulina, 2007.

MORIN, E. Educar na era planetária: o pensamento complexo como método de aprendizagem no erro e na incerteza humana. São Paulo: Cortez, Brasília, DF: UNESCO, 2009.

NUSSEnZVEIG, H. M. (Org.) Complexidade e caos. Rio de Janeiro: Editora UFRJ/ COPEA, 2003.

PRATS, S.; HERRERO, Y.; TORREGO, A. La Gran Encrucijada. Barcelona: Libros en Acción /Icaria, 2016.

PRIGOGINE, I. O nascimento do tempo. Rio de Janeiro: Edições 70, 1988.

PRIGOGINE, I. Enciclopédia Einaudi:Sistema. Portugal: Imprensa Nacional, Casa da moeda, 1993.

PRIGOGINE, I. O fim das certezas: tempo, caos e as leis da natureza. São Paulo: Editora da UNESP, 1996. 
PRIGOGINE, I.; STENGERS, I. A nova aliança. Brasília: Editora Universidade de Brasília, 1984.

PRIGOGINE, I.; STENGERS, I. Entre o tempo e a eternidade. São Paulo: Companhia das letras, 1992.

RODRIGUEZ-MARÍN, F; FERNÁNDEZ-ARROYO, J; GARCÍA, J. Las hipótesis de transición como herramienta didáctica para la educación ambiental. Enseñanza de Las Ciencias, v. 32, n. 3, p. 300-318, 2014.

SCHEIDER, E. E.; KAY, J. Ordem a partir da desordem: a termodinâmica da complexidade biológica. In: MURPHY; O’NEILL (Org.). O que é a vida? 50 anos depois. São Paulo: Editora UNESP, 1997. p. 186-201.

SEGURA, M. R. G.; RIBERAYGUA, M. F.; PUBILL, M. J. Competencias profesionales en educación para la sostenibilidad desde la complejidad. Enseñanza de las ciencias (X Congreso), Espanha, n. extra, p. 4863, 2017.

TAIBO, C. El colapso. Madrid: Los Libros de la Catarata, 2016.

WATANABE, G. Aspectos da complexidade: contribuições da Física para a compreensão do tema ambiental. 2012. 246 p. Tese (Doutorado em Ensino de Ciências) Universidade de São Paulo, São Paulo.

WATANABE, G.; KAWAMURA, M. R. D. Uma educação na perspectiva ambiental crítica, complexa e reflexiva. Revista Brasileira de Pesquisa em Educação em Ciências, São Paulo, v. 14, n. 2, p. 255-264, 2014.

WATANABE; RODRIGUEZ-MARÍN, F. Aspectos da complexidade nas questões socioambientais: as abordagens no Brasil e na Espanha. Ciência \& Educação, Bauru, v. 24, n. 3, p. 543-562, 2018. 